\title{
A Correlational Study on Translation Ability, Reading Habit and Writing Skill
}

\author{
Hafid Sukri Hernandani, Gunarso Susilohadi, and Hefy Sulistyawati
}

\author{
English Education Department \\ Teacher Training and Education Faculty \\ Sebelas Maret University of Surakarta
}

\author{
Email: Havidhernan@ rocketmail.com
}

\begin{abstract}
Numerous researches have viewed that translation, reading and writing as mutually reinforcing interactive processes in English as foreign language context. The aim of the article is to report an empirical study on the correlation between translation ability and reading habit toward writing skill either partially or simultaneously. The method used correlational study, with a test and a questionnaire as the technique of collecting data. The population was all of the eleventh grade students of SMA in Boyolali. The technique of choosing the sample was cluster random sampling. The techniques used to analyze the data are Simple and Multiple Linear Regression and Correlation. The research findings show that: (1) translation ability contributes to writing skill; (2) similar interaction is found between reading habit and writing skill; and (3) translation ability and reading habit simultaneously contribute to writing skill.
\end{abstract}

Keywords: translation ability, reading habit, writing skill, correlation

\section{INTRODUCTION}

The goal of language learning is to develop communicative competence in written and spoken communication which covers listening, speaking, reading, and writing skill. Writing is the most difficult skills for students to acquire. (Awg Nik et al, 2010:54). Furthermore, they also argue that "writing is unlike spoken language, as it requires the readers or the audience to understand and interpret what has been written". In addition, Awg Nik et al (2010:54) state that "writing is not just putting pen to a paper or writing down ideas but it is how these ideas are presented or expressed effectively". According to Bell and Burnby as quoted by Nunan (1998: 36), "writing is an extremely complex cognitive activity in which a writer is requires demonstrating control of a number of variables simultaneously". Therefore, the writers should use all sorts of linguistic devices to make their message or meaning clear. To communicate the message, they want readers to understand because they do not have face to face contact with their reader.

Moreover, students ${ }^{\text {ee }}$ writing ability refers to students competence in applying the components of writing including content, organization, vocabulary, language use (grammar), and mechanism (Jacob in Reid, 1993: 236-237). In addition, Widdowson (1996: 61) states that writing is described as the use of the medium to manifest the graphological and grammatical system of the language. By these ideas it can be concluded that writing 
skill in this study is defined as complex cognitive activity including the act of express and arranging the ideas into written form that have to be arranged according to certain conventions, which involves content, organization, vocabulary, grammar, and mechanics.

There are some problems and difficulties that arise in writing activities for EFL students. There are some factors that can improve writing skill of students. One of factors that can improve studentse writing skill is translation ability. According to Liao (2006: 195), "translation can help students to check whether their comprehension is correct and it eases memory constrains in memorizing more words, idioms, grammar, and sentence structure". Furthermore, Bagheri and Fazel (2011) in their study found that the use of translation can be a valuable resource or means which can pave the way for the development of the writing skill.

According to Dagiliene (2012: 124), "translation activities were applied in the foreign language learning process to achieve progress in improving language skills in reading, writing, speaking and listening". In the process of writing, when EFL students are writing English, actually they would involve their translation ability. In this case, perhaps they have ideas that still in from of Indonesian then beginning to translate from Indonesia into English as target language before write down to a paper. Basically, translation has good position in teaching and learning English as foreign language. Translation cannot be separated from other abilities.

Genesse and Upshur (1997:206) state that there are some important aspects to show students writing skill covering content, organization (cohesive, coherence), etc), vocabulary, language use (tenses), and mechanics (punctuation, spelling, etc). Furthermore, Schäffner (in M. Aqel, 2013: 2) gives lists the benefits of translation; (a) expand the students ${ }^{\text {ee }}$ vocabulary in L2, (b) develop their style, (c) improve their understanding of how languages work, (d) consolidate L2 structures for active use and (e) monitor and improve the comprehension of L2". It means that the students will get benefits from translation activity to support and solve their difficulties in a process of writing in EFL learning. It is supported by Sager (in Bagheri and Fazel, 2011: 292) who argues that "translation and writing are the closest parallel activities, and they share similarities in approach and features". In addition, Petrocchi (in Dagiliene, 2012: 126) states that "by translating activity the learners acquire more competence in the knowledge of grammatical structures".

Another factor that influences students $^{\text {ee }}$ writing skill is reading habit. Sangkaeo (in Noor 2011:2) states that "reading habit refers to the behaviour which expresses the likeness of reading of individual types of reading and tastes of reading. Meanwhile, Iftanti (2012: 150) states that a habit of reading is established by having frequent repetition of reading practices in a course of time. In addition, Shen (in Noor, 2011:2) identifies that reading habits as how often, how much, and what students read. Reading not only depends on knowledge or skill, but also on the student wanting to read (values and attitudes (Gaona and Gonzalez, 2010:58).

Reading is closely related to writing. It is supported by Awg Nik et al (2010: 54) who argues that "we believe that students who do not read and write well in their first language need to work harder on the new creative activity of 
Thank you for using www. freepdfconvert.com service! Only two pages are converted. Please Sign Up to convert all pages. https://www.freepdfconvert.com/membership 